\title{
Histopathology of Sinonasal and Nasopharyngeal Neoplastic Lesions in a Tertiary Care Center of Western Nepal: A Descriptive Cross-sectional Study
}

\author{
Sudeep Regmi, ${ }^{1}$ Arnab Ghosh, ' Dilasma Gharti Magar, ' Sushma Thapa, ${ }^{1}$ Krishna Prasad Koirala, ${ }^{2}$ Om \\ Prakash Talwar ${ }^{1}$
}

'Department of Pathology, Manipal Teaching Hospital, Phulbari, Pokhara, Nepal, ${ }^{2}$ Department of ENT-Head and Neck Surgery, Manipal Teaching Hospital, Phulbari, Pokhara, Nepal.

\section{ABSTRACT}

Introduction: Sinonasal and nasopharyngeal regions harbor diverse clinical conditions including many non-neoplastic and neoplastic lesions presenting with nasal obstruction, facial pain and swelling, rhinorrhea, epistaxis, and other oral, ear, and orbital symptoms. Histopathology of excised lesions is the mainstay for the definitive diagnosis and management of neoplastic lesions. The aim of this study is to find out the prevalence of neoplastic lesions among sinonasal and nasopharyngeal masses.

Methods: This was a descriptive cross-sectional study conducted among sinonasal and nasopharyngeal masses in the department of pathology of a tertiary care center of western Nepal with primary data of 20 years from January 2001 to May 2020. Ethical approval was taken from the Institutional Review Committee. Convenience sampling method was used. Data management and statistical analysis were done using Statistical Package for Social Sciences. Point estimate at 95\% Confidence Interval was calculated along with frequency and percentage.

Results: Out of 395 sinonasal and nasopharyngeal lesions, 134 (33.92\%) (29.26-38.58 at 95\% Confidence Interval) were neoplastic lesions. The malignant lesions were found to be $60(44.77 \%)$. Inverted papilloma was the most common benign lesion comprising $28(20.89 \%)$ of cases, and squamous cell carcinoma and nasopharyngeal carcinoma were the most common malignant lesions comprising 12 $(8.95 \%)$ cases each.

Conclusions: This study observed a variety of neoplastic lesions. The most common benign lesion was nasal polyp and squamous cell carcinoma and nasopharyngeal carcinoma were the most common malignant lesions.

\section{Keywords: histopathology; nasal cavity; nasal polyp; squamous cell carcinoma.}

\section{INTRODUCTION}

Sinonasal (SN) and nasopharyngeal (NAP) region harbors diverse clinical conditions ranging from different nonneoplastic to neoplastic lesions. ${ }^{1-4}$ Many of these lesions present as polypoidal masses with nasal obstruction, whereas other presenting symptoms may be facial swelling and pain, rhinorrhea, and epistaxis along with associated oral, ear and orbital symptoms. ${ }^{5-8}$

A presumptive diagnosis can be given on the basis of clinical symptoms and imaging techniques, but histopathology examination (HPE) is essential to confirm the definitive diagnosis. HPE can be taken as the gold standard to diagnose and categorize neoplastic lesions of the SN and NAP region. ${ }^{5,7}$

The aim of the study is to find out the prevalence of neoplastic lesions among sinonasal and nasopharyngeal masses.

Correspondence: Dr. Sudeep Regmi, Department of Pathology, Manipal College of Medical Sciences Teaching Hospital, Phulbari-11, Pokhara, Nepal. Email: sudeepregmi10@gmail.com, Phone:+977-9856055511. 


\section{METHODS}

This was a descriptive cross-sectional study conducted among patients with sinonasal and nasopharyngeal masses in the department of pathology, Manipal Teaching Hospital, Phulbari, Pokhara, Nepal with primary data of 20 years from January, 2001 to May, 2020. Ethical approval was obtained from the Institutional Review Committee prior to commencement of the study (MEMG/IRC/358/GA). Convenience sampling method was used and sample size was calculated using the formula,

Sample size calculation

$\mathrm{n}=\mathrm{Z}^{2} \times \mathrm{p} \times \mathrm{q} / \mathrm{e}^{2}$

$=1.96^{2} \times 0.5 \times(1-0.5) / 0.05^{2}$

$=384$

Where,

$\mathrm{n}=$ sample size

$Z=1.96$ at $95 \%$ Confidence Interval

$p=$ prevalence at $50 \%$ for maximum sample size

$q=1-p$

$e=$ margin of error, $5 \%$

The sample size 395 were taken for the study. Data was retrieved from the departmental archive and all the cases with histopathological evaluation of $\mathrm{SN}$ and NAP masses were involved in the study. Out of Table 1. Distribution of neoplastic lesions according to
1849 otolaryngorhinology cases referred to Pathology Department for HPE, 395 cases were of SN and NAP masses in last 20 years duration. About 37 cases presented with recurrence of the lesion. The study was recorded in Microsoft Excel with the help of a proforma. Data management and statistical analysis were done using Statistical Package for Social Sciences (SPSS ${ }^{\mathrm{TM}}$ ) software, version 20 . Point estimate at $95 \%$ Confidence Interval was calculated along with frequency and proportion for binary data.

\section{RESULTS}

Out of 395 SN and NAP masses, 134 (33.92\%) 29.26 - 38.58 at $95 \%$ Confidence Interval) were neoplastic lesions. The mean age of patients with neoplastic lesions was $48.54 \pm 21.31$ years $(49.14 \pm 21.43$ years for male) and $47.83 \pm 21.48$ years for female) ranging from 25 days to 92 years. Males comprised of 78 $(58.2 \%)$ cases, and the females were $56(41.7 \%)$ with a male to female ratio of $1.39: 1$.

Out of all neoplastic lesions, 60 (44.77\%) were malignant, $73(54.47 \%)$ were benign, and only one $(0.74 \%)$ of the cases was intermediate. Distribution of benign and malignant lesions according to the genderand age group are tabulated below (Table 1, 2).

\section{Type of Lesion}

Benign

Intermediate

Malignant*

Total

*Includes dysplastic lesions.

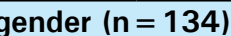

Gender

Female $\mathbf{n}(\%)$
$27(20.1)$
$1(0.7)$
$28(20.8)$
$56(41.7)$

$46(34.3)$

$0(0.0)$

32 (23.8)

$78(58.2)$

\begin{tabular}{|c|c|c|c|c|}
\hline \multirow[t]{2}{*}{ Age Group } & \multicolumn{3}{|l|}{ Type of Lesion } & \multirow[t]{2}{*}{ n (\%) } \\
\hline & Benign n (\%) & Intermediate $\mathrm{n}(\%)$ & Malignant* $n(\%)$ & \\
\hline$<10$ Years & $3(2.2)$ & $0(0.0)$ & $2(1.4)$ & $5(3.7)$ \\
\hline $11-20$ Years & $11(8.2)$ & $0(0.0)$ & $1(0.7)$ & $12(8.9)$ \\
\hline 21-30 Years & $15(11.1)$ & $0(0.0)$ & $0(0.0)$ & $15(11.1)$ \\
\hline 31-40 Years & $10(7.4)$ & $1(0.7)$ & $4(2.98)$ & $15(11.1)$ \\
\hline 41-50 Years & $10(7.4)$ & $0(0.0)$ & $7(5.2)$ & $17(12.6)$ \\
\hline 51-60 Years & $9(6.7)$ & $0(0.0)$ & $19(14.1)$ & $28(20.8)$ \\
\hline 61-70 Years & $9(6.7)$ & $0(0.0)$ & $13(9.7)$ & $22(16.4)$ \\
\hline$>70$ Years & $6(4.4)$ & $0(0.0)$ & $14(10.4)$ & $20(14.9)$ \\
\hline Total & $73(54.4)$ & $1(0.7)$ & 60 (44.7) & $134(100.0)$ \\
\hline
\end{tabular}

*Includes dysplastic lesions.

Among 134 cases, nasal cavity (NC) was the most common site of biopsy comprising 107 (79.8\%) of cases, followed by NAP 18 (13.4\%), and Paranasal Sinus (PNS) 4 (2.9\%). NC was also the commonest site for benign neoplasms comprising 65 (48.5\%) cases. Only one lesion of intermediate malignancy in the series also occurred in the NC. Distribution of lesions according to the site is given in the table below (Table $3)$.

In our study, inverted papilloma was the most common benign lesion comprising 28 (20.8\%) of total lesions, whereas squamous cell carcinoma (SCC) and nasopharyngeal carcinoma (NPC) were the most common malignant lesions comprising 12 (8.9\%) cases each. 


\begin{tabular}{|c|c|c|c|c|c|c|c|}
\hline \multirow[b]{2}{*}{ Lesion } & \multicolumn{7}{|c|}{ Site } \\
\hline & 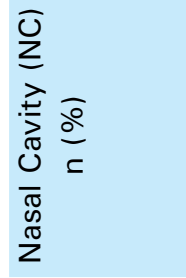 & 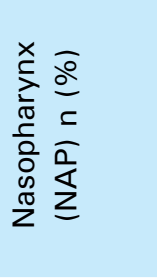 & 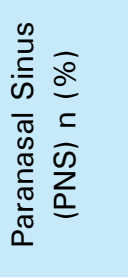 & $\begin{array}{l}\overline{0} \\
\vdots \\
0 \\
0 \\
+ \\
0 \\
z\end{array}$ & $\begin{array}{l}a \\
a \\
c \\
0 \\
z \\
0 \\
+ \\
u \\
z\end{array}$ & $\begin{array}{l}c \\
c \\
z \\
0 \\
+ \\
0 \\
n \\
+ \\
u \\
z\end{array}$ & $\begin{array}{l}\frac{a}{0} \\
\frac{1}{c} \\
\stackrel{0}{0} \\
1\end{array}$ \\
\hline Benign & $65(48.5)$ & $3(2.2)$ & $2(1.4)$ & 0 & $3(2.2)$ & 0 & $73(54.4)$ \\
\hline Intermediate & $1(0.7)$ & 0 & 0 & 0 & 0 & 0 & $1(0.7)$ \\
\hline Malignant* & 41 (30.5) & $15(11.1)$ & $2(1.4)$ & 0 & $1(0.7)$ & $1(0.7)$ & $60(44.7)$ \\
\hline Total & $107(79.8)$ & $18(13.4)$ & $4(2.9)$ & 0 & $4(2.9)$ & $1(0.7)$ & $134(100)$ \\
\hline
\end{tabular}

*Includes dysplastic lesions.

All the neoplastic lesions of the study are depicted. Only one $(0.7 \%)$ intermediate lesion occurred which was hemangioendothelioma (Table 4).

\begin{tabular}{|llll|}
\hline \multicolumn{2}{|l}{ Table 4. Neoplastic lesions of the study $(\mathbf{n}=134)}$. & & \\
\hline Lesion & $\mathbf{n}(\%)$ & Lesion & $\mathbf{n}(\%)$ \\
Benign Lesions & $73(54.4)$ & & $1(0.7)$ \\
Inverted Papilloma & $28(20.8)$ & Meningioma & $1(0.7)$ \\
Capillary Hemangioma & $23(17.1)$ & Nevus & $1(0.7)$ \\
Angiofibroma & $8(5.9)$ & Nasal Glioma & $1(0.7)$ \\
Squamous Papilloma & $7(5.2)$ & Sebaceous Adenoma & $1(0.7)$ \\
Cavernous Hemangioma & $2(1.4)$ & Trichoepithelioma & $1(0.7)$ \\
Intermediate Lesions & $1(0.7)$ & & $2(1.4)$ \\
Epithelioid Hemangioendothelioma & & & $2(1.4)$ \\
Malignant Lesions & $60(44.7)$ & & $2(1.4)$ \\
Squamous Cell Carcinoma & $12(8.9)$ & Olfactory Neuroblastoma & $2(1.4)$ \\
Nasopharyngeal Carcinoma & $12(8.9)$ & Positive for Malignancy & $1(0.7)$ \\
Basal Cell Carcinoma & $6(4.47)$ & Rhabdomyosarcoma & $1(0.7)$ \\
Sinonasal Undifferentiated Carcinoma & $5(3.7)$ & Sinonasal Adenocarcinoma & $1(0.7)$ \\
Non-Hodgkin Lymphoma & $5(3.7)$ & Malignant Peripheral Nerve Sheath Tumor & $1(0.7)$ \\
Adenoid Cystic Carcinoma & $3(2.2)$ & Osteosarcoma & \\
Malignant Melanoma & $3(2.2)$ & Poorly Differentiated Carcinoma & \\
Inverted Papilloma with Dysplasia & $2(1.4)$ & Nasal Polyp with Dysplasia & \\
\hline
\end{tabular}

\section{DISCUSSION}

Nasal cavity (NC), paranasal sinuses (PNS) and nasopharynx (NAP) harbors a variety of neoplastic lesions. ${ }^{4,9,10}$ In the present study, there was a male preponderance with a male to female ratio of 1.39:1. Other similar studies also showed a male predominance. ${ }^{4,9,10}$ In contrast, study of Parajuli S. et al. done in the central region of the country, and that of Bakari A. et al. from Nigeria showed female predominance. . $^{2,11}$

Benign lesions were most prevalent in the study comprising $54.47 \%$ of cases, whereas $44.7 \%$ of the cases were malignant. Majority of the studies also showed benign lesions as the most prevailing lesions, and the prevalence of malignant lesions ranged from $2.6 \%$ to as high as $43.8 \% .^{2,5,9-13}$ Neoplastic lesion occurring in the minimum age of our study ( 25 days) was found to be a benign lesion viz. capillary hemangioma.
Age-wise prevalence showed a fairly uniform distribution of lesions from the 2 nd decade till the 7 th decade, after which there is a decline in the incidence. The malignant lesions are seen increasing only after the 6th decade. Other studies also show a comparable observation and showed increase in prevalence of malignant lesions only after the 5 th decade of life..$^{3,10,11,14}$

Inverted papilloma (INP) was the most prevalent benign neoplastic lesion in the current study comprising $20.89 \%$ of all benign lesions. Studies done by Bakari A, et al. and Garg, et al. showed comparable observations. ${ }^{2,9}$ Different to our finding, hemangioma was the most common benign neoplasm in the study of Lathi A. et al, and capillary hemangioma in the study of Parajuli S, et al. ${ }^{10,11}$ INPs are characterized by local invasion, tendency for recurrence, and their association with malignancy. ${ }^{15}$ Study done by Krouse $\mathrm{JH}$ found squamous cell carcinoma (SCC) associated with INP in 
Regmi et al. Histopathology Sinonasal and Nasopharyngeal Neoplastic Lesions in a Tertiary Care Center of Western Nepal...

$9.1 \%$ of the cases, whereas Weissler MC, et al. and Lawson $W$, et al. reported $4.72 \%$ and $5.74 \%$ cases of malignancy respectively. ${ }^{16-18}$ Two cases $(1.4 \%)$ in our study showed dysplasia in INP. These lesions might serve as a precursor lesion for SCC.

Current study also observed $1(0.7 \%)$ case each of meningioma and nasal glioma (NG). Extracranial meningiomas (ECM) are rare and found primarily in the head and neck region involving ear, nose and PNS. ${ }^{19}$ Primary ECMs comprise less than $2 \%$ of all meningiomas, and their pathogenesis is not completely established. Entrapment of meningocytes during closure of midline structures creating disconnection with the neuraxis and formation of ectopic site for arising ECMs is postulated. ${ }^{20} \mathrm{NGs}$ also arise from abnormal embryonal development. Radiological investigation is essential to exclude extracranial extension. ${ }^{21}$

This study showed $60(44.77 \%)$ malignant cases of neoplastic cases. Similar to our finding, Wang $X$, et al. observed $43.8 \%$ malignant cases in their study, whereas study of Parajuli S, et al. and Singh SG found only $6.7 \%$ and $9 \%$ malignant lesions respectively. ${ }^{1,11,13}$ The prevalence of malignant lesions varies according to the geographical regions along with ethnic and cultural differences. Malignant lesions arising in the sinonasal and nasopharyngeal region may be confused with nasal polyps or other chronic inflammatory lesion causing delay in the diagnosis and management. ${ }^{9}$

Most common malignancies in the current study were SCC and nasopharyngeal carcinoma (NPC) comprising $8.9 \%$ each of all the lesions. Study of Jaison J, et al. also revealed $6.73 \%$ SCC as the primary malignancy. However, their study didn't have a single case of NPC among 104 cases studied over a period of 5 years. ${ }^{22}$ Similarly, study of Raj JA, et al. also showed SCC as their most common malignancy. ${ }^{8} \mathrm{SN}$ and NAP region comprise only $3-5 \%$ of all head and neck malignancies, and SCC is the most common subtype consisting more than $50 \%$ of cases. ${ }^{23,24}$ Although the pathogenesis of SCC is poorly understood, carcinogen exposure due to occupational hazards, viral oncogenesis related to Human Papilloma Virus, INP as a precursor lesion, and a state of ongoing chronic inflammation are related towards the causation of SCC in the sinonasal and nasopharyngeal region. ${ }^{24,25}$

Study of Begum MS, et. al confirmed NPC as the most common malignant lesion comprising $18.18 \%$ of the cases, whereas in the study of Khan N, et al. it was the second most common malignancy comprising $4.16 \%$ of all lesions. ${ }^{26,27}$ NPC is a malignancy with poor prognosis, and has a distinct geographical distribution and is mostly centered in east and southeast Asia. Dietary habits, lifestyle, and environmental exposures including role of Epstein Barr Virus (EBV) are the related factors. ${ }^{28} \mathrm{EBV}$ DNA can be used for screening people in endemic areas, as well as in the prognostic implementation, predicting treatment response, and disease surveillance. ${ }^{29}$

Present study found that sinonasal undifferentiated carcinoma (SNUC) comprised $5(3.7 \%)$ cases. Study of Khan $\mathrm{N}$, et al. showed presence of $3.12 \%$ SNUC in their study, whereas study of Parajuli S, et al. didn't show a single case of SNUC. ${ }^{11,26}$ SNUC is a malignancy with a propensity to metastasize, and usually presents at advanced stage leading to usually a poor prognosis with higher rates of recurrence. Despite advances in different modalities of treatment, the survival remains poor. 30

Non-Hodgkin lymphoma (NHL) also comprised 5 (3.7\%) of all cases in the study. Almost similar to our findings, study of Boer CV, et al. showed $0.12 \% \mathrm{NHL}$, Khan $\mathrm{N}$, et al. observed $2 \% \mathrm{NHL}$, and Parajuli $\mathrm{S}$, et al. found the incidence of lymphoma to be $3 \%$ in their study. ${ }^{11,26,31}$ In contrast, Zhu L, et al. showed $21.7 \%$ incidence of NHL. ${ }^{32}$ $\mathrm{NHL}$ in the sinonasal and nasopharyngeal regions are uncommon and range from different B-cells and T-cells lymphomas to Natural Killer/T-cell lymphomas. ${ }^{33}$ Many studies have pointed out diffuse large B-cell Lymphoma as the most common lymphoma in these anatomic regions. ${ }^{34-36}$ Immunohistochemistry and flowcytometry are two essential diagnostic modalities to sub-classify NHL leading to targeted therapy. However, due to lack of these facility, only morphological classification using National Cancer Institute working formulation were reported. ${ }^{37}$

Salivary gland-type adenoid cystic carcinoma and primary nasal mucosal melanoma comprised 3 cases $(2.23 \%)$ each. Other malignant lesions like olfactory neuroblastoma, rhabdomyosarcoma, and sinonasal adenocarcinoma comprised 2 cases $(1.49 \%)$ each, whereas 1 cases each $(0.74 \%)$ of malignant peripheral nerve sheath tumor and osteosarcoma were seen. One of the case $(0.74 \%)$ was signed out as poorly differentiated carcinoma, as it could not be further subclassified on histopathology. These malignant lesions are seen in a more or less similar fashion of incidence, or were absent throughout many studies. ${ }^{2,3,5,10,11,26}$ Although these malignant lesions are not common, identification in histopathology is crucial for their proper management.

\section{CONCLUSIONS}

The sinonasal and nasopharyngeal anatomic region encompassed different neoplastic lesions in our study. Inverted papilloma was the most common benign lesion whereas both squamous cell carcinoma 
Regmi et al. Histopathology Sinonasal and Nasopharyngeal Neoplastic Lesions in a Tertiary Care Center of Western Nepal...

and nasopharyngeal carcinoma constituted the predominant malignant lesions. Histopathologic analysis of biopsy specimens is key to their final definitive diagnosis leading to their early and appropriate management, especially in the cases of malignant lesions. Screening can also be carried out for presence of any masses in older adults or elderly people.

\section{Conflict of Interest: None.}

\section{REFERENCES}

1. Singh SG, Qureshi S, Jain L, Jadia S, Sharma S. Presentation of Lesions of Nose and Paranasal Sinuses at a Tertiary Care Center in Central India. Indian J Otolaryngol Head Neck Surg. 2018 Jun;70(2):284-9. [uued | Full Text | DOI]

2. Bakari A, Afolabi OA, Adoga AA, Kodiya AM, Ahmad BM. Clinico-pathological profile of sinonasal masses: an experience in national ear care center Kaduna, Nigeria. BMC Res Notes. 2010 Jul 9;3:186. [PubMed | Full Text | DOI]

3. Ajiya A, Abdullahi H, Shuaibu IY. Clinicopathologic profile of sinonasal neoplasia in Kano, Northwestern Nigeria: A 10-year single-institution experience. Ann Afr Med. 2020 Sep;19(3):191-7. [ PubMed | Full Text | DOI]

4. Zafar U, Khan N, Afroz N, Hasan SA. Clinicopathological study of non-neoplastic lesions of nasal cavity and paranasal sinuses. Indian J Pathol Microbiol. 2008 Mar;51(1):26-9. [PubMed $\mid$ Full Text $\mid \underline{\text { DOI] }}$

5. Bist SS, Varshney S, Baunthiyal V, Bhagat S, Kusum A. Clinico-pathological profile of sinonasal masses: An experience in tertiary care hospital of Uttarakhand. Natl J Maxillofac Surg. 2012 Jul;3(2):180-6. [PubMed | Full Text | $\underline{\mathrm{DOI}}]$

6. Tan BK, Kern RC, Schleimer RP, Schwartz BS. Chronic Rhinosinusitis: The Unrecognized Epidemic. Am J Respir Crit Care Med. 2013 Dec 1;188(11):1275-7. [ubMed | Full Text | DOI]

7. Modh SK, Delwadia KN, Gonsai RN. Histopathological spectrum of sinonasal masses-A study of 162 cases. Int J Cur Res Rev. 2013;5(3):83-91. [Full Text]

8. Raj JA, Sharmila PS, Shrivastava M, Mahantachar V, Rajaram T. Morphological spectrum of lesions in the sinonasal region. J Evol Med Dent Sci. 2013;2(37):7175-87. [ull Text | DOI]

9. Garg D, Mathur K. Clinico-pathological Study of Space Occupying Lesions of Nasal Cavity, Paranasal Sinuses and Nasopharynx. J Clin Diagn Res. 2014 Nov;8(11):FC04-07. [PubMed | Full Text | DOI]

10. Lathi A, Syed MM, Kalakoti P, Qutub D, Kishve SP. Clinico-pathological profile of sinonasal masses: a study from a tertiary care hospital of India. Acta Otorhinolaryngol Ital. 2011 Dec;31(6):372-7. [PubMed | Full Text]

11. Parajuli S, Tuladhar A. Histomorphological spectrum of masses of the nasal cavity, paranasal sinuses and nasopharynx. J Pathol Nepal. 2013 Mar 27;3(5):351-5. [Full Text $\mid$ DOI]

12. Humayun AHP, Huq AZ, Ahmed ST, Kamal MS, Bhattacharjee N. Clinicopathological study of sinonasal masses. Bangladesh J Otorhinolaryngol. 2010;16(1):15-22. [Full Text | DOI]
13. Wang X, Shi G, Liu Y, Ji H, He M, Li J, et al. [Analysis of the clinical and pathological characteristics of sinonasal neoplasms]. Lin Chuang Er Bi Yan Hou Tou Jing Wai Ke Za Zhi J Clin Otorhinolaryngol Head Neck Surg. 2011 Dec;25(23):1071-5. [PubMed]

14. Poursadegh M, Poursadegh F, Esmaeili M, Bakhshaee M. Epidemiological Survey of Sinonasal Malignancy in North-East Iran. Iran J Otorhinolaryngol. 2015 May;27(80):225-9. [PubMed | Full Text]

15. Melroy CT, Senior BA. Benign sinonasal neoplasms: a focus on inverting papilloma. Otolaryngol Clin North Am. 2006 Jun;39(3):601-17, x. [PubMed | DOI]

16. Lawson W, Le Benger J, Som P, Bernard PJ, Biller HF. Inverted papilloma: an analysis of 87 cases. The Laryngoscope. 1989 Nov;99(11):1117-24. [PubMed | DOI]

17. Krouse JH. Endoscopic treatment of inverted papilloma: safety and efficacy. Am J Otolaryngol. 2001;22(2):87-99. [PubMed | DOI]

18. Weissler MC, Montgomery WW, Turner PA, Montgomery SK, Joseph MP. Inverted papilloma. Ann Otol Rhinol Laryngol. 1986 Jun;95(3 Pt 1):215-21. [uued | DOI]

19. Landini G, Kitano M. Meningioma of the mandible. Cancer. 1992 Jun 15;69(12):2917-20. [PubMed | DOI]

20. Aiyer RG, Prashanth V, Ambani K, Bhat VS, Soni GB. Primary Extracranial Meningioma of Paranasal Sinuses. Indian J Otolaryngol Head Neck Surg. 2013 Aug;65(Suppl 2):384-7. [PubMed | Full Text | DOI]

21. Ma KH, Cheung KL. Nasal glioma. Hong Kong Med J. 2006 Dec;12(6):477-9. [라bMed | Full Text]

22. Jaison J, Tekwani DT. Histopathological lesions of nasal cavity, paranasal sinuses and nasopharynx. Ann Appl Bio-Sci. 2015;2(2):40-6. [Full Text]

23. Ansa B, Goodman M, Ward K, Kono SA, Owonikoko TK, Higgins $K$, et al. Paranasal sinus squamous cell carcinoma incidence and survival based on Surveillance, Epidemiology, and End Results data, 1973 to 2009. Cancer. 2013 Jul 15;119(14):2602-10. [PubMed | Full Text | DOI]

24. Elgart K, Faden DL. Sinonasal Squamous Cell Carcinoma: Etiology, Pathogenesis, and the Role of Human Papilloma Virus. Curr Otorhinolaryngol Rep. 2020 Jun;8(2):111-9.

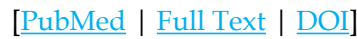

25. Lewis JS. Sinonasal Squamous Cell Carcinoma: A Review with Emphasis on Emerging Histologic Subtypes and the Role of Human Papillomavirus. Head Neck Pathol. 2016 Feb 1;10(1):60-7. [PubMed | Full Text | DOI]

26. Khan N, Zafar U, Afroz N, Ahmad SS, Hasan SA. Masses of nasal cavity, paranasal sinuses and nasopharynx: A 
Regmi et al. Histopathology Sinonasal and Nasopharyngeal Neoplastic Lesions in a Tertiary Care Center of Western Nepal...

clinicopathological study. Indian J Otolaryngol Head Neck Surg. 2006 Jul;58(3):259-63. [PubMed | Full Text | DOI]

27. Begum MS, Sarker UK, Islam MA, Sangma MA, Paul P, Rahman MA. Magnetic Resonance Imaging in Evaluation of Sinonasal Masses with Histopathological Correlation. Mymensingh Med J. 2018 Jan;27(1):26-33. [PubMed]

28. Lee HM, Okuda KS, González FE, Patel V. Current Perspectives on Nasopharyngeal Carcinoma. Adv Exp Med Biol. 2019;1164:11-34. [PubMed | DOI]

29. Chen Y-P, Chan ATC, Le Q-T, Blanchard P, Sun Y, Ma J. Nasopharyngeal carcinoma. Lancet Lond Engl. 2019 Jul 6;394(10192):64-80. [PubMed | DOI]

30. Abdelmeguid AS, Bell D, Hanna EY. Sinonasal Undifferentiated Carcinoma. Curr Oncol Rep. 2019 Feb 26;21(3):26. [ [PubMed | DOI]

31. Van den Boer C, Brutel G, de Vries N. Is routine histopathological examination of FESS material useful? Eur Arch Otorhinolaryngol. 2010 Mar;267(3):381-4. [PubMed | Full Text | DOI]

32. Zhu L, Fang P, Liu Y, Tong B. [Clinical and diagnosis analysis of malignant lymphoma in nasal cavity and paranasal sinus]. Lin Chuang Er Bi Yan Hou Tou Jing Wai Ke Za Zhi. 2015 Feb;29(3):255-7. [PubMed]
33. Abdelwahed Hussein MR. Non-Hodgkin's lymphoma of the oral cavity and maxillofacial region: a pathologist viewpoint. Expert Rev Hematol. 2018 Sep;11(9):737-48. [마bMed | Full Text | DOI]

34. Steele TO, Buniel MC, Mace JC, El Rassi E, Smith TL. Lymphoma of the nasal cavity and paranasal sinuses: A case series. Am J Rhinol Allergy. 2016 Sep;30(5):335-9. [PubMed | Full Text | DOI]

35. Peng KA, Kita AE, Suh JD, Bhuta SM, Wang MB. Sinonasal lymphoma: case series and review of the literature. Int Forum Allergy Rhinol. 2014 Aug;4(8):670-4. [라Med | Full Text $\mid \underline{\mathrm{DOI}}]$

36. Hsueh C-Y, Yang C-F, Gau J-P, Kuan EC, Ho C-Y, Chiou T-J, et al. Nasopharyngeal Lymphoma: A 22-Year Review of 35

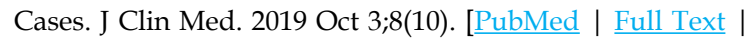
DOI]

37. Swerdlow SH, Cook JR. As the world turns, evolving lymphoma classifications-past, present and future. Hum Pathol. 2020 Jan;95:55-77. [PubMed | Full Text | DOI]

This work is licensed under a Creative Commons Attribution 4.0 International License. The images or other third party material in this article are included in the article's Creative Commons license, unless indicated otherwise in the credit line; if the material is not included under the Creative Commons license, users will need to obtain permission from the license holder to reproduce the material. To view a copy of this license, visit http://creativecommons.org/licenses/by/4.0/ 